\title{
Usefulness of the Modified NRCS-CN Method for the Assessment of Direct Runoff in a Mountain Catchment
}

\author{
Andrzej WAŁĘGA ${ }^{1}$ and Agnieszka RUTKOWSKA ${ }^{2}$ \\ ${ }^{1}$ Department of Sanitary Engineering and Water Management, \\ University of Agriculture in Krakow, Kraków, Poland; \\ e-mail: a.walega@ur.krakow.pl \\ ${ }^{2}$ Department of Applied Mathematics, University of Agriculture in Krakow, \\ Kraków, Poland
}

\begin{abstract}
The aim of this study was to evaluate the usefulness of modified methods, developed on the basis of NRCS-CN method, in determining the size of an effective rainfall (direct runoff). The analyses were performed for the mountain catchment of the Kamienica river, right-hand tributary of the Dunajec. The amount of direct runoff was calculated using the following methods: (1) Original NRCS-CN model, (2) MishraSingh model (MS model), (3) Sahu-Mishra-Eldho model (SME model), (4) Sahu 1-p model, (5) Sahu 3-p model, and (6) Q_base model. The study results indicated that the amount of direct runoff, determined on the basis of the original NRCS-CN method, may differ significantly from the actually observed values. The best results were achieved when the direct runoff was determined using the SME and Sahu 3-p model.
\end{abstract}

Key words: direct runoff, NRCS method, antecedent moisture condition (AMC), hydrological models, base flow. 


\section{INTRODUCTION}

The rainfall-runoff process is a complex, dynamic and nonlinear process, affected by many, often interrelated physical factors. Reliable predictions of quantity and rate of runoff from land surface into streams and rivers are difficult and time-consuming to obtain for ungauged watersheds. As a result, many researchers have developed various methods to estimate both, the human influence on changes in surface runoff, especially storm runoff, and consequent effects on downstream activities (Fan et al. 2013).

In the recent years, the rainfall-runoff models have been commonly used to simulate the hydrological phenomena in uncontrolled catchments. By using these methods, it is not only possible to calculate the design flows necessary for the design of hydraulic facilities, but also to determine the flood parameters (duration, time to peak, wave volume, etc.), and to analyze the catchment response to the changes triggered, e.g., by human activities. However, hydrological modeling requires an input consisting of a large number of parameters that are sometimes difficult to determine. One of the characteristics to be provided as the input data to a model is the effective rainfall intensity. The Soil Conservation Service Curve Number (SCS-CN) method (SCS 1956) (now National Resources Conservation Service NRCS) is one of the most popular methods for computing the surface runoff depth for a given rainfall event from small watersheds. Although the SCS-CN method was originally developed in the United States and mainly for the evaluation of storm runoff in small agricultural watersheds, it soon evolved well beyond its original objective. Its scope also expanded beyond the evaluation of storm runoff and it became an integral part of more complex, long term simulation models (Chauhan et al. 2013).

This method is simple and easy to apply. The primary reason for its wide applicability and acceptability is the fact that it accounts for major runoff generating catchment characteristics, namely soil type, land use/treatment, surface conditions, and antecedent moisture conditions (Deshmukh et al. 2013, Mishra and Singh 2002, 2003a,b; Ponce 1989, Váňová and Langhammer 2011, Merz and Blöschl 2009). Many researchers developed CN calculation methods by incorporating land cover information and the original CN in TR-55 (Fan et al. 2013). Hong and Adler (2008) developed a global SCS-CN runoff map using land cover, soils, and antecedent moisture conditions.

The SCS-CN method is widely used by engineers, hydrologists, and watershed managers as a simple watershed model, and as a runoff estimating component in more complex watershed models (Deshmukh et al. 2013). Ponce and Hawkins (1996) claimed that the SCS-CN method was a conceptual model of hydrologic abstraction of storm rainfall, supported by empiri- 
cal data. Kabiri et al. (2013) claimed that the runoff values determined by means of SCS-CN method did not differ from those calculated with GreenAmpt method. Petroselli et al. (2013) and Grimaldi et al. (2013) proposed a method combining the Green-Ampt infiltration equation and calibration of both the ponding time and the soil hydraulic conductivity, using the initial abstraction and the total volume given by the SCS-CN method. The soil conservation service curve number (NRCS-CN) method converts rainfall to surface runoff (or rainfall-excess) using the $\mathrm{CN}$ derived from catchment characteristics and a 5-day antecedent rainfall. This model is chosen for predicting the runoff, because it is a well-known procedure that has been used for many years around the world. It is computationally efficient, the required inputs are generally available, and it relates the runoff to the soil type, land use, and management practices. To derive $\mathrm{CN}$ values (valid for storm duration shorter than 1 day) for an ungauged catchment, NRCS provided tables based on the soil type, land cover and land use, hydrological conditions, and antecedent moisture condition (AMC) (Cunha et al. 2011, Maidment 1993, Mishra et al. 2013).

As shown by the works of Wałega et al. $(2011,2012)$, correct determination of $\mathrm{CN}$ parameter is crucial when preparing the data for the calculations, since the hydrological models are sensitive to changes in this parameter (McCuen 2003). Research conducted on the applicability of the NRCS-CN method suggested a need for its improvement (Efstratiadis et al. 2014, Miler 2012, Ponce and Hawkins 1996, Caviedes-Voullième et al. 2012. Garen and Moore (2005) and Woodward et al. (2010) indicated that NRCS-CN method was not applicable at sub-daily time resolution and should not be employed for estimating water infiltration into soil, mainly because it is a lumped approach (considering space and time), developed in order to define the total direct runoff derived from a rainfall event. Although several modifications to this method have been suggested and reported in the literature (Chauhan et al. 2013, Mishra et al. 2005), further improvements are still needed. The greatest limitations of the original NRCS-CN method are as follows: the three AMC levels used with this method permit unreasonable sudden jumps in $\mathrm{CN}$ and hence corresponding sudden jumps in the computed runoff are possible; there is a lack of clear guidance on how to vary antecedent moisture conditions; and there is no explicit dependency between the initial abstraction and the antecedent moisture (Sahu et al. 2012). Smith and Williams (1980) modified the SCS-CN method and suggested the expression for a retention parameter $S$ by introducing a weighing factor to account for the soil moisture in the soil profile, in order to avoid sudden quantum jumps in the $\mathrm{CN}$ values when shifting from one AMC level to the other. Michel et al. (2005) critically reviewed the soil moisture accounting procedure behind SCS-CN method and unveiled major inconsistencies in the treatment of an- 
tecedent condition in SCS-CN procedure. Geetha et al. (2007) made an attempt to obviate sudden jumps in $\mathrm{CN}$ values when chaining from one $\mathrm{AMC}$ level to other by modifying the existing SCS-CN method in two ways: varying the $\mathrm{CN}$ using antecedent moisture condition and using antecedent moisture amount. However, as shown by numerous studies on the application of the original NRCS-CN method for calculating the effective rainfall (Banasik and Woodward 2010, Ebrahimian et al. 2012, Krzanowski et al. 2013), CN parameter values, specified theoretically and according to NRCS guidelines, are significantly different from those calculated empirically, based on the recorded rainfall-runoff events. Unfortunately, many designers unknowingly use the original method in their hydrological calculations, which can result in a significant underestimation of the actual flood parameters. Therefore, it seems necessary to verify the application of the NRCS-CN method in the local conditions, to reduce the uncertainty of modeling results and promote more common use of this method in practice.

The aim of this study was to evaluate the usefulness of modified methods, developed on the basis of the NRCS-CN method, in determining the size of the effective rainfall (direct runoff) in a mountain catchment.

\section{CATCHMENT DESCRIPTION}

The study was conducted in the catchment area of the Kamienica river, which is a right-hand tributary of the Dunajec and enters it in the city of Nowy Sacz. This catchment is located in the southern Poland. It is a part of three mesoregions: Beskid Sądecki - upper part of the catchment, Beskid Niski and Kotlina Sacecka - middle and lower part of the catchment. The riverhead is located in the Beskid Sądecki at a height of $859.5 \mathrm{~m}$ a.m.s.l. The total length of the river is $33.1 \mathrm{~km}$ and the catchment area up to the entry into the Dunajec is $237.8 \mathrm{~km}^{2}$. The catchment area includes alluvial soils, river sands and gravels, as well as shales, marls, and sandstones. They were formed from noncarbonate decomposed sedimentary rocks. The catchment of the Kamienica river is dominated by forests that cover about $60 \%$ of its area, mainly in the upper part; arable lands account for approximately $7 \%$, grasslands cover more than $7 \%$, built-up areas occupy about $8 \%$ of the catchment, with the highest concentration around the Kamienica entry into the Dunajec (Fig. 1). The annual precipitation in the investigated catchment is $850 \mathrm{~mm}$.

\section{MATERIALS AND METHODS}

Input material for the analysis consisted of selected rainfall-runoff events recorded for the upper part of the Kamienica catchment, closed with Łabowa water-level indicator (catchment area $64.9 \mathrm{~km}^{2}$ ). Rainfall data with a time 


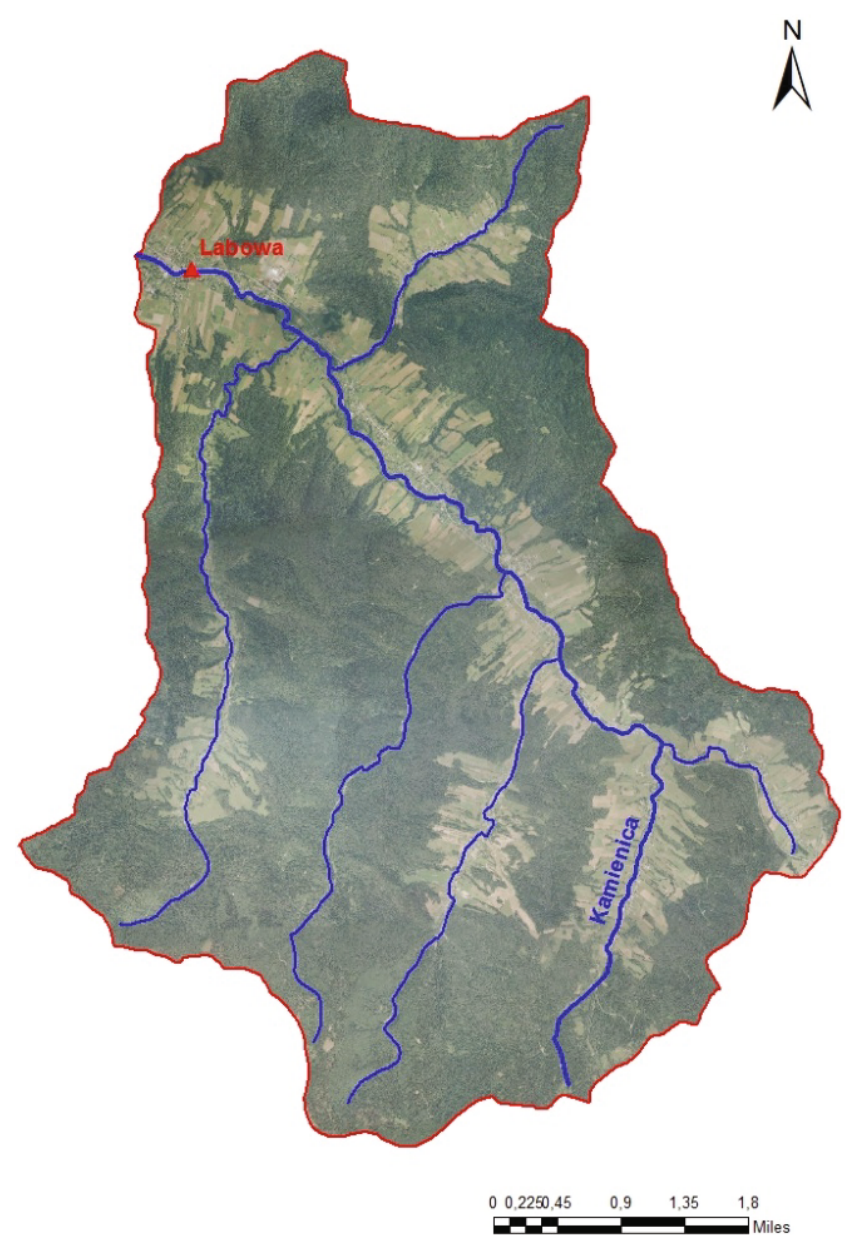

Fig. 1. The Kamienica catchment.

step of 24 hours were collected at a rainfall station in Krynica. The analysis included the greatest floods that occurred in the years 1997-2010, with a time step of 24 hours. The data were obtained from the Institute of Meteorology and Water Management - National Research Institute in Warsaw. Flood selection was based on a criterion of the lowest among the maximum annual flows (the period in which the instantaneous flows were higher than the threshold flow was selected for analysis). In total, 67 floods were recorded in the investigated multi-year period. As a result of data analyses and verification, the file analysis included 36 rainfall-runoff episodes. The dataset was divided into two subsets: the first, containing 30 episodes, was used for parameter calibration, and the second, containing 6 episodes, was used 
for validation. Before the actual analysis, the data on the base runoff and direct runoff were separated. This was made by drawing a straight line on a hydrograph from the point where the flow increase begins to the point on the descending part, where the direct runoff ends. This procedure allowed us to determine the actual amount of the direct runoff layer for individual episodes. In the next step, a theoretical amount of the direct runoff was calculated, using the following methods: (1) Original NRCS-CN model, (2) Mishra-Sighn model (MS model), (3) Sahu-Mishra-Eldho model (SME model), (4) Sahu 1-p model, (5) Sahu 3-p model, and (6) Q_base model.

\subsection{Original NRCS-CN model}

The SCS-CN method is based on the water balance equation and two fundamental hypotheses. The first hypothesis (1) equates the ratio of actual amount of direct surface runoff $Q$ to the total precipitation $P$ (or maximum potential surface runoff) to the ratio of actual infiltration $F$ to the amount of the potential maximum retention $S$. The second hypothesis relates the initial abstraction $I_{a}$ to the potential maximum retention $S$ (Deshmukh et al. 2013):

$$
\frac{Q}{P-I_{a}}=\frac{F}{S} \text {. }
$$

A general form of the NRCS-CN model is expressed by the following equations:

$$
\begin{gathered}
Q=\frac{\left(P-I_{a}\right)^{2}}{P-I_{a}+S} \text { if } P>I_{a}, \\
Q=0 \quad \text { otherwise } \\
I_{a}=\lambda S,
\end{gathered}
$$

where $Q$ is the direct runoff [mm], $P$ the total precipitation [mm], $I_{\mathrm{a}}$ the initial abstraction [mm], $S$ the potential maximum retention $[\mathrm{mm}]$, and $\lambda$ the initial abstraction coefficient (dimensionless).

The parameter $S$ of the NRCS-CN method depends on soil type, land use, hydrological conditions, and antecedent moisture condition (AMC). The parameter $S$ is expressed as:

$$
S=\frac{25400}{\mathrm{CN}}-254,
$$

where $S$ is in $\mathrm{mm}$ and $\mathrm{CN}$ is the curve number, which depends on the soil type, land cover and land use, hydrological conditions, and antecedent moisture condition (AMC). 


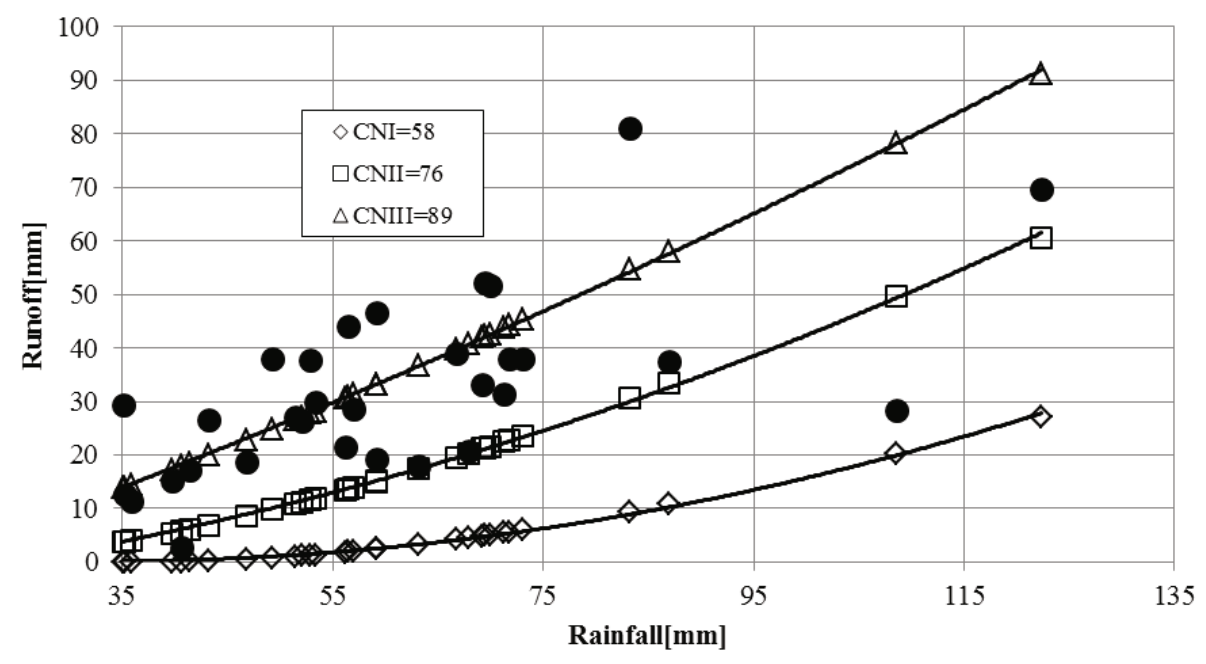

Fig. 2. Development of rainfall-runoff relation versus $\mathrm{CN}$ value according to the original NRCS-CN method.

$\mathrm{CN}=100$ represents a condition of zero potential maximum retention $(S=0)$, that is, an impermeable watershed. Conversely, $\mathrm{CN}=0$ represents a theoretical upper bound to potential maximum retention $(S=1)$, that is an infinitely abstracting watershed.

A theoretical value of $\mathrm{CN}$ parameter was determined based on an orthophoto, with reference to current land use and 1:25000 scale soil maps. It was found to correspond to normal catchment moisture conditions AMCII. The $\mathrm{CN}$ parameter for the two other antecedent moisture conditions, i.e., AMCI and AMCIII (Hawkins et al. 1985), was determined using appropriate tables. The catchment AMC was determined for each event according to the distribution of the points with rainfall-runoff coordinates relative to the theoretical runoff values (see Fig. 2). This way, the direct runoff was calculated according to NRCS-CN_PNWemp method.

Calculated values of $\mathrm{CN}$ were determined based on the observed rainfallrunoff events. For this purpose, the total runoff hydrograph was divided into the groundwater (base) runoff and the surface runoff. Empirical value of retention $S_{i}[\mathrm{~mm}]$ is a solution of Eqs. 2 and 3 at $\lambda=0.201$. The analysis assumed the value of $\lambda$ established as a result of the calibration based on rainfall-runoff episodes.

$$
S_{i}=5 \cdot\left(P_{i}+2 \cdot H_{i}-\sqrt{4 \cdot H_{i}^{2}+5 \cdot P_{i} \cdot H_{i}}\right),
$$


where $P_{i}$ is the total precipitation amount causing $i$ floods [mm], and $H_{i}$ is the direct runoff $[\mathrm{mm}]$. The value of $\mathrm{CN}$ parameter was calculated according to the formula:

$$
\mathrm{CN}=\frac{25400}{254+S} .
$$

Runoff volume as NRCS- $\mathrm{CN}_{\text {calc }}$ was calculated using formula 2.

\subsection{Mishra-Singh model (MS model)}

Mishra and Singh (2002) modified the equation for direct runoff with antecedent moisture $M$ to:

$$
Q=\frac{\left(P-I_{a}\right)\left(P-I_{a}+M\right)}{P-I_{a}+M+S},
$$

where $M$ is the antecedent moisture $[\mathrm{mm}]$ :

$$
M=0.5 \cdot\left[-(1+\lambda S)+\sqrt{\left(1-\lambda^{2}\right) S^{2}+4 P_{5} S}\right] .
$$

Here, $I_{a}$ is the same as in Eq. 3 and $P_{5}$ denotes the amount of antecedent 5-day rainfall. Equation 8 represents the amount of moisture $M$ added to the dry soil profile by rain $P_{5}$. According to Sahu et al. (2010) the drawbacks of MS model can be summarized as follows:

- There is no explicit dependency of $I_{a}$ on $M$. It is known, however, that $I_{a}$ relies on interception, surface storage and infiltration, and all these factors greatly depend on $M$. The larger the $M$, the smaller the $I_{a}$, and the other way round;

- In Eq. 7, S is optimized as a parameter, which, however, is a varying quantity for a given watershed. Hence, it is not clear which moisture level/ condition the optimized $S$ would correspond to;

$\checkmark$ Evapotranspiration and other interim water losses are not accounted for.

In Eq. 8, the value of the maximum potential retention $S$ was adopted, according to the AMC and $\mathrm{CN}$, from the original NRCS-CN method. The parameter $\lambda$ in Eq. 8 was calibrated based on recorded rainfall-runoff episodes.

\subsection{Sahu-Mishra-Eldho model (SME model)}

Though the MS model obviates sudden jumps in $\mathrm{CN}$ with AMC and hence seems to be a continuous model, it needs refinements. Sahu et al. (2010) presented the following equations for the direct runoff: 


$$
\begin{gathered}
Q=\frac{\left(P-I_{a}\right)\left(P-I_{a}+M\right)}{P-I_{a}+S_{0}} \text { if } P>I_{a}, \\
Q=0 \quad \text { otherwise } \\
I_{a}=\lambda\left(S_{0}-M\right),
\end{gathered}
$$

where $S_{0}$ is the absolute maximum retention capacity. Equation 10 gives an explicit relationship between $I_{a}$ and $M$, and thus it is a continuous function (the higher the antecedent moisture $M$, the lower the initial abstraction $I_{a}$, and vice versa). When $\beta$ and $S_{0}$ are assumed as parameters, then $M$ is given as follows:

$$
\begin{aligned}
& M=\beta\left[\frac{\left(P_{5}-\lambda S_{0}\right) S_{0}}{\left(P_{5}-\lambda S_{0}\right)+S_{0}}\right] \text { for } P_{5}>\lambda S_{0}, \\
& M=0 \text { for } P_{5}<\lambda S_{0} .
\end{aligned}
$$

The SME model proposed by Sahu et al. (2010) has the following advantages over the MS model:

- The proposed SME model uses more rational continuous expression for estimating the antecedent moisture $M$. It restricts the validity of $M$ being equal to zero for $P_{5}<\lambda S_{0}$, and therefore $M$ is never negative;

The SME model explicitly relates $I_{a}$ with $M$, while MS and SCS-CN models do not;

- The proposed SME model allows optimization of $S_{0}$, an intrinsic parameter, and thus a constant quantity for a specific watershed. $S_{0}$ can be more rationally linked with watershed characteristics, while the MS model allows optimizing $S$, a varying parameter for a specific watershed.

In this method, $\lambda, S_{0}$, and $\beta$ were optimized. Root mean square error (RMSE), expressed by formula 23, was assumed as a goal function, and the optimization involved minimization of this function value. Due to difficulties in calibrating the parameters of SME model in uncontrolled catchments, the method was modified by making an assumption that $S_{0}=S$. The maximum potential catchment retention $S$ was adopted exactly in the same way as in MS model. Thus, the calibrated value of $\lambda$ in formula 10 represents the ratio of the absolute maximum retention capacity.

\subsection{Sahu 1-p model}

Since the three AMC levels used with the original SCS-CN method permit unreasonable sudden jumps in $\mathrm{CN}$, a continuous equation is needed to estimate the antecedent moisture. Sahu et al. (2007) developed two versions of a 
model determining the volume of direct runoff in the form of an equation comprising one or three parameters.

Given the simulations carried out in 82 catchments in India, $\alpha$ and $\beta$ parameters in the three-parameter model were 0.1 and 0.4 , mean and median values for each of these two parameters were almost the same, and these simplifications yielded a one-parameter model - Sahu 1-p, which is described by the following set of equations:

$$
\begin{aligned}
V_{0} & =0.4 P_{5} \quad \text { if } \quad P_{5} \leq 0.1 S, \\
V_{0} & =S\left(\frac{0.44 P_{5}-0.004 S}{P_{5}+0.9 S}\right) \text { if } P_{5}>0.1 S,
\end{aligned}
$$

where $V_{0}$ is the soil moisture store level at the beginning of the rainfall event $[\mathrm{mm}]$. Other symbols are as in the previous formulas. When $V_{0}$ is known, $Q$ can be computed as follows:

$$
\begin{aligned}
& \text { if } \quad V_{0}+P \leq 0.1 S \text { then } Q=0, \\
& \text { if } 0.1 S<V_{0}+P \leq 0.1 S+P \text { then } Q=\frac{\left(P+V_{0}-0.1 S\right)^{2}}{\left(P+V_{0}+0.9 S\right)}, \\
& \text { if } 0.1 S \leq V_{0} \leq 1.1 S \text { then } Q=P\left(1-\frac{\left(1.1 S-V_{0}\right)^{2}}{S^{2}+\left(1.1 S-V_{0}\right) P}\right) .
\end{aligned}
$$

The value of $S$ parameter was assumed in a similar way as in the abovementioned methods.

\subsection{Sahu 3-p model}

The antecedent or initial soil moisture $V_{0}$ depends not only on $P_{5}$ but also on $S$. The dependency on $S$ is based on the fact that the watershed with larger retention capacity $S$ must retain higher moisture compared to the watershed with lesser $S$ for a given $P_{5}$. In the derivation of an expression for $V_{0}$, the following assumptions are made:

a The pre-antecedent moisture level $\left(V_{00}\right) 5$ days before the onset of rainfall is zero or a fraction of $S$;

a The initial soil moisture store level $\left(V_{0}\right)$ at the time of the beginning of rainfall storm is equal to the sum of pre-antecedent moisture level $\left(V_{00}\right)$ and a fraction $\beta$ of the part of rainfall that is not transformed into runoff $\left(P_{5}-\right.$ $Q$ ) owing to rainfall of $P_{5}$ at the time, where $Q$ is the corresponding runoff. This assumption is based on the fact that only a fraction, in general, of mois- 
ture/water added to the soil will contribute to $V_{0}$ due to evapotranspiration losses in the previous 5 days.

Using suitable assumptions, Sahu et al. (2007) derived the following equations for different conditions:

$$
\begin{aligned}
& V_{0}=V_{00}+\beta P_{5} \text { for } V_{00} \leq S_{a}-P_{5}, \\
& V_{0}=V_{00}+\beta\left[P_{5}-\frac{\left(P_{5}+V_{00}-S_{a}\right)^{2}}{P_{5}+V_{00}-S_{a}+S}\right] \text { for } S_{a}-P_{5}<V_{00} \leq S_{a}, \\
& V_{0}=V_{00}+\beta P_{5}\left[\frac{\left(S+S_{a}-V_{00}\right)^{2}}{S^{2}+\left(S+S_{a}-V_{00}\right) P_{5}}\right] \text { for } S_{a} \leq V_{00} \leq S_{a}+S,
\end{aligned}
$$

where $V_{00}$ is the old moisture level available for 5 days before the rainfall, $S_{a}$ is an intrinsic parameter of soil moisture $\left(S_{a}=\alpha \cdot S\right)$, and $\beta$ is an additional model parameter ranging from 0 to 1 . Analyses performed by these authors indicated that $V_{00}=0$. This simplification in the Sahu model resulted into a three parameter model that is referred to as the Sahu 3-p model. The direct runoff was calculated using the following equations:

$$
\begin{aligned}
& Q=0 \text { for } V_{0} \leq S_{a}-P_{5}, \\
& Q=\frac{\left(P+V_{0}-0.1 S_{a}\right)^{2}}{P+V_{0}-S_{a}+S} \text { for } S_{a}-P_{5}<V_{0} \leq S_{a}, \\
& Q=P\left[1-\frac{\left(S+S_{a}-V_{0}\right)^{2}}{S^{2}+\left(S-S_{a}-V_{0}\right) P}\right] \text { for } S_{a} \leq V_{0} \leq S_{a}+S .
\end{aligned}
$$

This method involved optimization of $\alpha$ and $\beta$ parameters. Root mean square error (RMSE), expressed by formula 23 was assumed as a goal function, and the optimization involved minimization of this function.

\section{6 $Q$ base model}

Krzanowski et al. (2013) assumed that in a precipitation-free period or in the case of average rainfall, the watercourses were supplied by underground waters from the first aquifer level. Therefore, the knowledge on the base flow from before the flood period can provide sufficient information on the catchment moisture content. Higher values of the base flow may indicate high level of groundwater, and hence reduced retention capacity of the catchment. For this purpose, the authors made attempts at correlating the 
base flow $Q b$ with $\mathrm{CN}$ parameter values according to the original NRCS-CN method.

$\mathrm{CN}$ parameter values were determined from Eqs. 5 and 6. The parameters of the established relationship were determined using the least squares method. Direct outflow volume was calculated from Eqs. 2 and 4.

Assessment of a model's prediction accuracy is an important issue in hydrological modelling. In the present study, we used the root mean square error (RMSE) and Nash-Sutcliffe model efficiency (EF) (Nash and Sutcliffe 1970) as model goodness of fit to assess the model performance. These criteria are expressed as below:

$$
\begin{aligned}
\operatorname{RMSE} & =\sqrt{\frac{1}{N} \sum_{i=1}^{N}\left(Q_{\mathrm{obs}, i}-Q_{\mathrm{calc}, i}\right)^{2}}, \\
\mathrm{EF} & =1-\frac{\sum_{i=1}^{N}\left(Q_{\mathrm{obs}, i}-Q_{\mathrm{calc}, i}\right)^{2}}{\sum_{i=1}^{N}\left(Q_{\mathrm{obs}, i}-\overline{Q_{\mathrm{calc}, i}}\right)^{2}},
\end{aligned}
$$

where RMSE is in mm, EF is dimensionless. $Q_{\text {obs }}$ is the observed storm runoff [mm], $Q_{\text {calc }}$ is the calculated runoff [mm], $\overline{Q_{\text {obs }}}$ is a mean of the observed runoff values in the catchment, $N$ is the total number of rainfall-runoff events, and $i$ is an integer varying from 1 to $N$.

Additionally, significance of differences between the runoffs calculated using the analyzed methods was established. The calculations were performed using ANOVA with $\mathrm{F}$ test at a significance level $\alpha=0.05$. The differences between average value of $\mathrm{CN}_{\text {calc }}$ parameter and empirical values of $\mathrm{CN}_{\text {emp }}$, determined based on NRCS tables for the three AMC levels, were evaluated. For this purpose, Student's t test was used, testing the null hypothesis $H_{0}$ that the average $\mathrm{CN}_{\text {calc }}$ was equal to $\mathrm{CN}_{\text {emp }}$ for three AMC: $\mathrm{CN}_{\text {cal }}=\mathrm{CN}_{\text {emp_}}$ AMCI, $\mathrm{CN}_{\text {cal }}=\mathrm{CN}_{\text {emp_ }} \mathrm{AMCII}$, and $\mathrm{CN}_{\text {cal }}=\mathrm{CN}_{\text {emp_ }} \mathrm{AMCIII}$, against the hypothesis $H_{A}$ that the average values were different: $\mathrm{CN}_{\text {cal }} \neq$ $\mathrm{CN}_{\text {emp_ }} \mathrm{AMCI}, \quad \mathrm{CN}_{\text {cal }} \neq \mathrm{CN}_{\text {emp__ }} \mathrm{AMCII}$, and $\mathrm{CN}_{\text {cal }} \neq \mathrm{CN}_{\text {emp }}$ AMCIII. The null hypothesis was tested at a significance level $\alpha=0.05$. The statistical analyses were performed in Statistica for Windows 10.0.

\section{RESULTS}

Table 1 summarizes main parameters of the analyzed floods. The greatest direct runoff was recorded for episode No. 25 that occurred in the third decade of July 2004. This flood was caused by a precipitation episode lasting 4 days, with total depth exceeding $83.2 \mathrm{~mm}$. The rainfall for the analyzed floods in the catchment ranged from 28.4 to $108.6 \mathrm{~mm}$, the runoff was from 2.8 to $81.1 \mathrm{~mm}$, and the sum of five-day rainfall $P_{5}$ ranged from 0.0 to 
Table 1

Basic characteristics of the analyzed floods

\begin{tabular}{|c|c|c|c|}
\hline No. & $\begin{array}{l}\text { Total precipitation } \\
{[\mathrm{mm}]}\end{array}$ & $\begin{array}{l}\text { Direct runoff } \\
{[\mathrm{mm}]}\end{array}$ & $\begin{array}{l}\text { Precipitation within } 5 \text { days } \\
\text { preceding the flood } \\
{[\mathrm{mm}]}\end{array}$ \\
\hline 1 & 66.7 & 39.1 & 7.5 \\
\hline 2 & 56.2 & 21.5 & 7.9 \\
\hline 3 & 108.6 & 28.3 & 0.2 \\
\hline 4 & 87.0 & 37.5 & 12.8 \\
\hline 5 & 57.0 & 28.5 & 26.2 \\
\hline 6 & 69.9 & 51.6 & 5.8 \\
\hline 7 & 73.0 & 38.0 & 1.5 \\
\hline 8 & 41.4 & 17.1 & 0.5 \\
\hline 9 & 20.8 & 17.7 & 2.5 \\
\hline 10 & 59.2 & 19.2 & 41.1 \\
\hline 11 & 51.4 & 27.0 & 42.6 \\
\hline 12 & 39.7 & 15.2 & 37.0 \\
\hline 13 & 29.1 & 23.0 & 7.8 \\
\hline 14 & 53.3 & 30.0 & 9.2 \\
\hline 15 & 31.5 & 22.8 & 0.5 \\
\hline 16 & 40.6 & 2.8 & 13.4 \\
\hline 17 & 69.2 & 33.3 & 53.6 \\
\hline 18 & 28.4 & 13.8 & 21.6 \\
\hline 19 & 35.2 & 12.7 & 25.0 \\
\hline 20 & 56.5 & 44.2 & 0.0 \\
\hline 21 & 67.9 & 20.7 & 25.1 \\
\hline 22 & 71.2 & 31.3 & 13.5 \\
\hline 23 & 43.2 & 26.5 & 8.8 \\
\hline 24 & 35.1 & 29.3 & 0.3 \\
\hline 25 & 83.2 & 81.1 & 23.7 \\
\hline 26 & 52.1 & 26.3 & 36.0 \\
\hline 27 & 71.7 & 37.9 & 61.7 \\
\hline 28 & 28.6 & 21.9 & 8.7 \\
\hline 29 & 59.1 & 46.7 & 0.1 \\
\hline 30 & 52.9 & 37.8 & 5.3 \\
\hline
\end{tabular}


$61.7 \mathrm{~mm}$. In the investigated mountain catchment, 49 out of 67 floods occurred in the summer half of the year, which accounted for $73 \%$ of all episodes. Most of the floods were recorded in July and August. This flood distribution throughout the year is typical of mountain catchments located in southern Poland.

Figure 2 shows observation-based rainfall-runoff correlations for the analyzed episodes, with relation to limit curves calculated for $\mathrm{CN}$ parameter, determined theoretically for three moisture levels. The theoretical value of $\mathrm{CN}$ parameter for normal moisture conditions was 76 . The analyses showed that both empirically determined values of $\mathrm{CN}$ parameter and the calculated volumes of direct runoff for 28 analyzed episodes fell within the area of $\mathrm{CN}$ theoretical curve for the third moisture level, often exceeding the upper limit. According to NRCS, in 30 out of 36 analyzed flood events, soil moisture corresponded to level I.

The computed parameter values for all the analyzed models for the Kamienica catchment are presented in Table 2. In order to optimize the model parameters, we used the "Solver" tool available in Microsoft Office Excel. Based on detailed calculations, a logarithmic function was adopted to describe the relationships between base flow and $\mathrm{CN}$ :

$$
\mathrm{CN}\left(Q_{b}\right)=4.909 \ln Q_{b}+90.59 \text {. }
$$

In the case of $Q_{-}$base model, the calculated correlation coefficient for Eq. 25) was 0.821 and the coefficient of determination was 0.679 . Figure 3 presents the relationship between $Q_{b}$ and CN. It was found that the increased

Table 2

Parameter values in various models for the Kamienica catchment

\begin{tabular}{|l|c|c|}
\hline \multicolumn{1}{|c|}{ Model } & Parameter & Value \\
\hline \multirow{2}{*}{ Original NRCS-CN ${ }_{\text {calc }}$} & $\begin{array}{c}\mathrm{CN}_{\text {med }}{ }^{*} \\
\lambda\end{array}$ & $\begin{array}{r}88.500 \\
\end{array}$ \\
\hline \multirow{2}{*}{ MS Model } & $\lambda$ & 0.201 \\
\hline \multirow{2}{*}{ SME Model } & $\lambda$ & 0.010 \\
& $\beta$ & 0.010 \\
\hline \multirow{2}{*}{ Sahu 1-p model } & - & - \\
\hline \multirow{2}{*}{ Sahu 3-p model } & $A$ & 0.217 \\
& $\beta$ & 0.010 \\
\hline \multirow{2}{*}{$Q$ base model } & $A$ & 4.909 \\
& $b$ & 90.590 \\
\hline
\end{tabular}

*) median value of empirical $\mathrm{CN}$ 


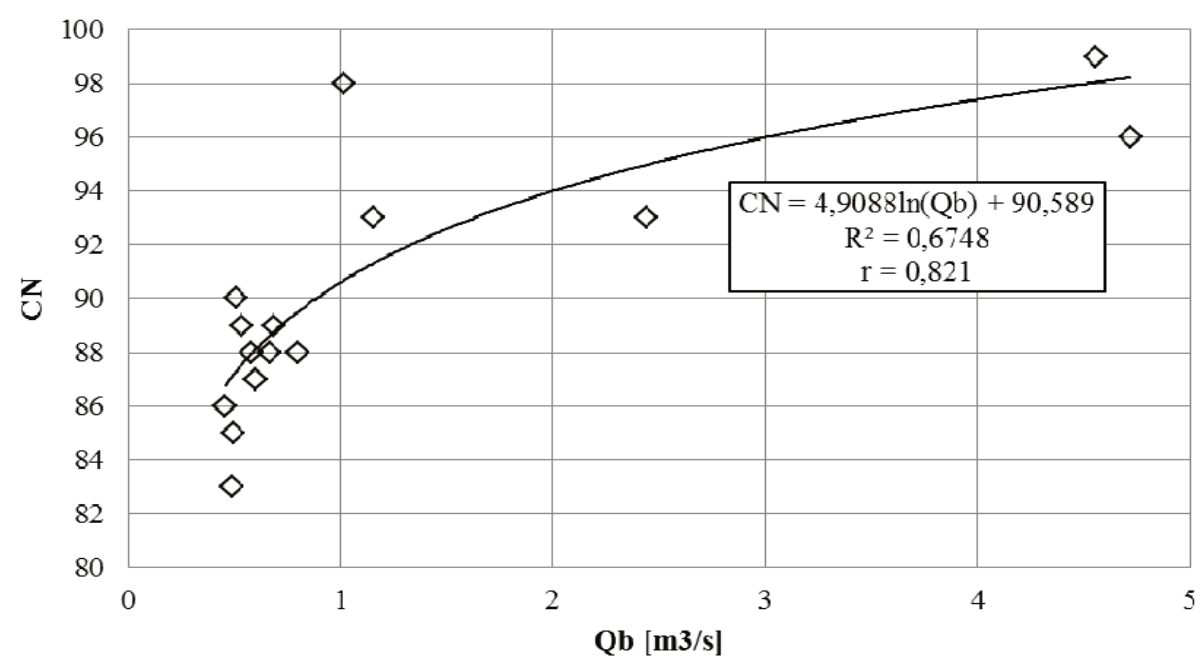

Fig. 3. Relation between empirical $\mathrm{CN}$ values and base flow before the floods.

base flow (and thus reduced retention capacity of the catchment) was accompanied by higher $\mathrm{CN}$ values.

Table 3 shows the quality assessment results for the presented models. The higher the RMSE, the poorer the performance of the model, and vice versa, $\mathrm{RMSE}=0$ means a perfect fit. The EF value of unity indicates perfect agreement between the observed and computed values, and decreasing values indicate poorer agreement. This measure implies that the model predicts no better than the average of the observed data. The value of model efficiency can be negative, which indicates that the average observed value is a

Table 3

Performance of the quality models for the Kamienica catchment

\begin{tabular}{|l|r|c|r|c|}
\hline \multirow{2}{*}{ Model } & \multicolumn{2}{|c|}{ Calibration } & \multicolumn{2}{c|}{ Verification } \\
\cline { 2 - 5 } & $\begin{array}{c}\text { RMSE } \\
{[\mathrm{mm}]}\end{array}$ & EF & $\begin{array}{c}\text { RMSE } \\
{[\mathrm{mm}]}\end{array}$ & EF \\
\hline $\begin{array}{l}\text { Original NRCS-CN } \\
\text { (CN calibrated) }\end{array}$ & 0.61 & 0.998 & 13.16 & 0.61 \\
Original NRCS-CN_PNW & & & & 0.85 \\
MS Model & 9.40 & 0.57 & 8.02 & 0.70 \\
SME Model & 11.54 & 0.37 & 11.39 & 0.61 \\
Sahu 1-p model & 8.54 & 0.65 & 6.61 & 0.90 \\
Sahu 3-p model & 10.03 & 0.52 & 5.95 & 0.92 \\
$Q_{\text {_base model }}$ & 8.49 & 0.65 & 6.59 & 0.90 \\
\hline
\end{tabular}


better estimate than the model predicted, that is, the model prediction is worse than the average observation (Sahu et al. 2012).

Our calculations showed that model 1, based on the original NRCS-CN equation, with $\mathrm{CN}$ parameter calibration, the most accurately characterized the amount of the direct runoff. The calibration process yielded RMSE error of only $0.61 \mathrm{~mm}$, and the coefficient of effectiveness EF was 0.998. In turn, when the model assumed average $\mathrm{CN}_{\mathrm{cal}}$, determined during the calibration, the calculations for the floods selected for verification showed much worse model performance, i.e., $13.16 \mathrm{~mm}$ for RMSE and 0.61 for EF. Assuming the AMC level determined for the observed episodes (Fig. 2), the maximum potential retention $S$ was calculated for empirical CN values specified with reference to the catchment use and soil conditions. Then, the size of the runoff was calculated from formula 2. Qualitative assessment of this model for the episodes used for calibration was much worse than for the model with calibrated CN $(\mathrm{RMSE}=9.40 \mathrm{~mm}, \mathrm{EF}=0.57)$. The situation was opposite for the verification, where the model performance was much better. Analysis of the modification of the original NRCS-CN method revealed that the calibration process provided the best quality for $Q$ base model, with $\mathrm{RMSE}=$ $4.38 \mathrm{~mm}$ and $\mathrm{EF}=0.85$. The other good models were SME and Sahu 3-p ones. The weakest score was achieved by MS model. All modifications of NRCS model based on verification, except for $Q$ base model, were rated better than in the case of calibration. The highest scores were obtained by Sahu 1-p, Sahu 3-p, and SME models, and the lowest by $Q$ base model, for which the $\mathrm{EF}=-0.39$ indicated that the average observed flow provided better results than the calculated flow.

Figure 4 presents typical fitting of all considered models for the Kamienica catchment for calibration, and Fig. 5 for verification. It is apparent from this figure that the runoff values calculated using NRCS_CN $\mathrm{CN}_{\text {cal }}, \mathrm{SME}$, and $Q$ base model were the closest to the corresponding observed values, and closer than those calculated using other models for most of the events. Hence, these three models performed equally well and better than the other models. The greatest differences in the results from SME and $Q$ base models can be seen for the greatest floods, while the calculation results are relatively reliable for the medium and small depth runoffs. The largest floods are best described by single parameter models NRCS-CN ${ }_{\text {cal }}$. Assuming the criteria presented by Moriasi et al. (2007) for calibration, MS model shall be deemed unsatisfactory $(\mathrm{EF}<0.50)$, NRCS-CNPNW ${ }_{\text {emp }}, \mathrm{SME}$, Sahu 1-p, Sahu 3-p are satisfactory $(0.50<\mathrm{EF} \leq 0.65)$, and $Q$ base and $\mathrm{NRCS}_{-} \mathrm{CN}_{\text {cal }}$ models are very good $(\mathrm{EF}>0.75)$. Figure 5 shows the fitting of the analyzed models to the observations in the case of verification. The best fitting was obtained for the SME and Sahu 1-p models. It can be concluded that for low values of observed runoff, the theoretical runoff yielded from the models is 


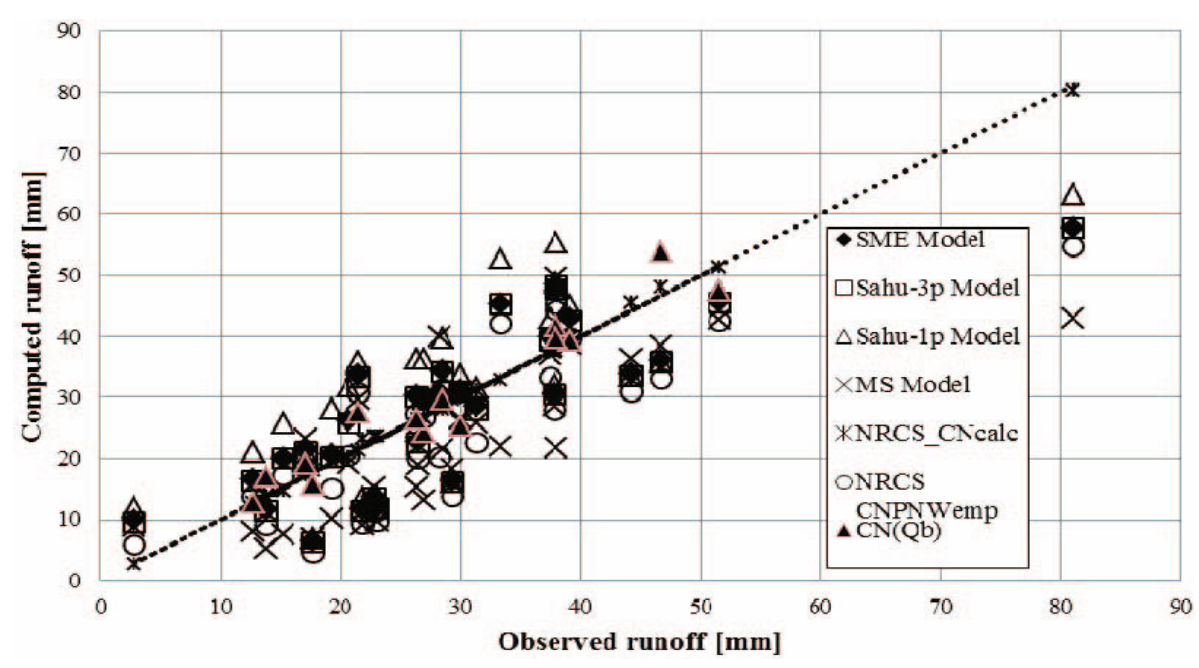

Fig. 4. Fitting of the original NRCS CN method and the modified models to the Kamienica catchment for calibration.

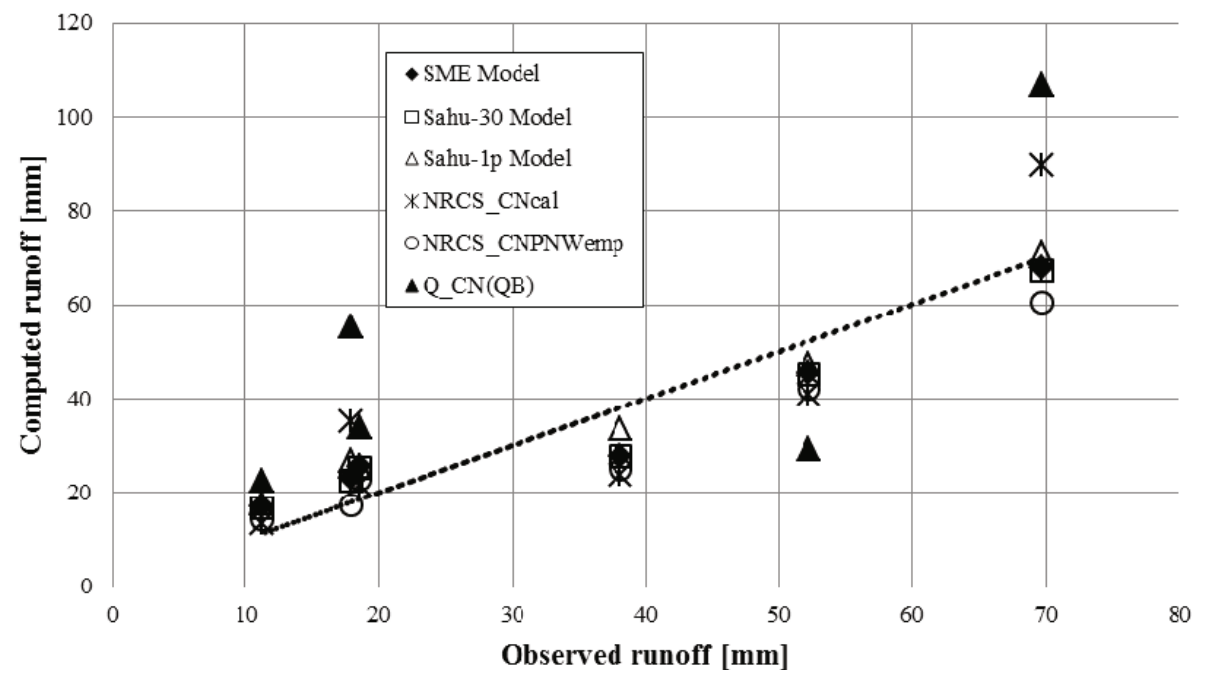

Fig. 5. Fitting of the original NRCS CN method and the modified models to the Kamienica catchment for the verification.

slightly overestimated, and for higher observed runoffs it is underestimated. In the case of verification, NRCS-CN $\mathrm{N}_{\text {cal }}$ is satisfactory, the MS model is good $(0.65<\mathrm{EF} \leq 0.75)$, and the other models are very good.

Figure 5 and Table 4 show the significance of differences between the direct runoff values estimated using a variety of methods. Calculations showed 
Results of $\mathrm{F}$ test for the significance of differences between mean values of reduction coefficients in the analyzed methods

\begin{tabular}{|c|c|c|c|c|}
\hline Method & SS & MS & F & $p[\%]$ \\
\hline & 1355.60 & 271.10 & 1.53 & 0.18 \\
\hline
\end{tabular}

Explanations: SS - sum of squares between groups, MS - mean squares between groups, $\mathrm{F}-\mathrm{F}$ test value, $p$ - probability level (at $\mathrm{p}<0.05$ significant values).

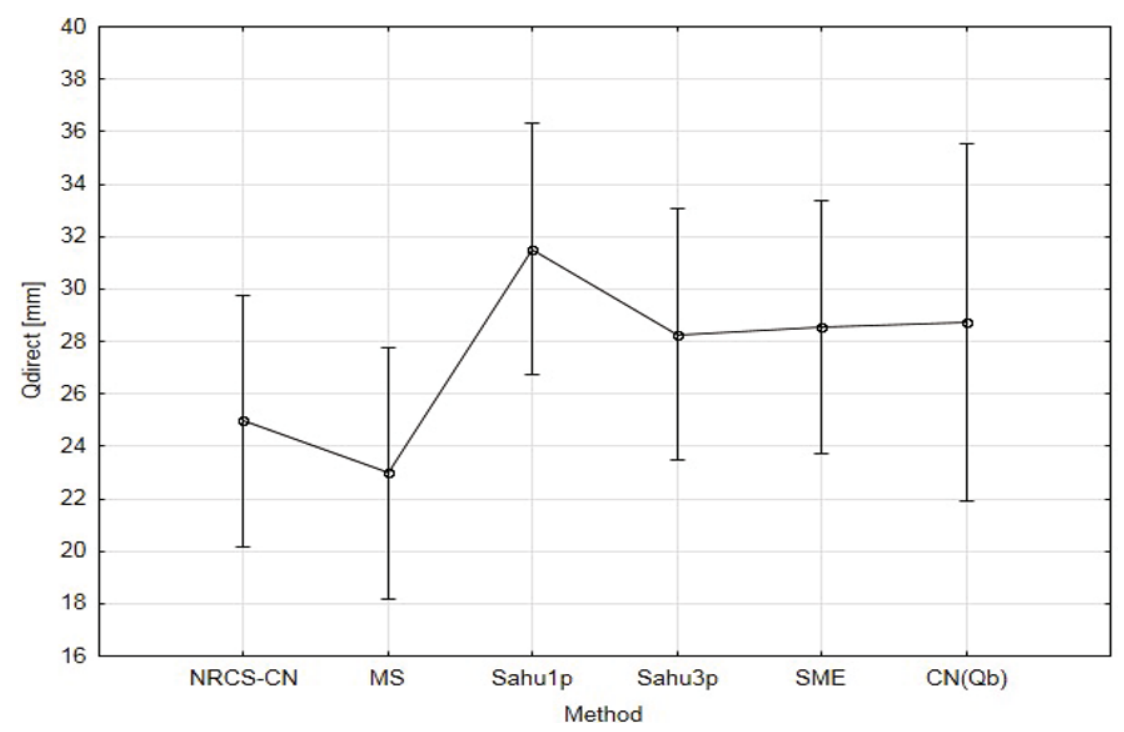

Fig. 6. Means and deviations of the direct runoff values determined for various methods.

that $\mathrm{F}$ was equal to 1.53 , and was greater than the critical value, which indicated a lack of significant differences between the average runoffs estimated by means of different methods. The highest average runoff was calculated using Sahu 1-p method, and the lowest using MS model (Fig. 6).

Its values were very similar in SME, Sahu 3-p and CN(QB) models. Student's t test was used to evaluate the average value of $\mathrm{CN}_{\text {cal }}$ in relation to empirical values of $\mathrm{CN}_{\mathrm{emp}}$ for three AMC levels. Calculations showed that in the case of $\mathrm{CN}_{\mathrm{emp}}$ corresponding to AMCIII, there were no reasons to reject the null hypothesis $H_{0}: \mathrm{CN}_{\text {cal }}=\mathrm{CN}_{\text {emp_PNWIII at a significance level }}$ $\alpha=0.05$.

The results of Student's $t$ test were as follows: $t=-0.718, p=0.477$. For the remaining AMC levels, there was no basis for accepting the null hypothesis $H_{0}$ : $\mathrm{CN}_{\text {cal }}=\mathrm{CN}_{\text {emp_}}$ PNWI and $\mathrm{CN}_{\text {cal }}=\mathrm{CN}_{\text {emp_- }}$ PNWII. As a result, 
the alternative hypothesis $H_{A}$ was accepted: $\mathrm{CN}_{\text {cal }} \neq \mathrm{CN}_{\text {emp_AMCI }}, \mathrm{CN}_{\mathrm{cal}} \neq$ $\mathrm{CN}_{\text {emp_}}$ AMCII. The results of Student's $\mathrm{t}$ test were as follows: for the hypothesis $\mathrm{CN}_{\text {cal }} \neq \mathrm{CN}_{\text {emp_ }}$ AMCI $t=21.549, p=0.00$, and for the hypothesis $\mathrm{CN}_{\text {cal }} \neq \mathrm{CN}_{\text {emp }}$ AMCII $t=8.62, p=0.00$. The presented results indicated that when calculating the effective rainfall with NRCS method in uncontrolled catchments with similar characteristics as the analyzed one, $\mathrm{CN}_{\mathrm{emp}}$ value should correspond to AMCIII.

\section{DISCUSSION}

The conducted analyses showed significant differences between the runoff volumes calculated using the proposed model and based on the actual values. These results confirm the reports of other authors (Banasik and Woodward 2010), claiming that in normal conditions the empirically determined $\mathrm{CN}$ is significantly higher than the calculated $\mathrm{CN}$. This means that, in the case of the investigated catchment, the rainfall reached already moist soil. The catchment soil moisture level was determined not only by the precipitation, but also by high level of ground water table that could be maintained after the winter period, leading to reduced catchment retention capacity, as well as poorly permeable soils that made precipitation infiltration more difficult. In practice, when modeling floods and estimating the depth of the effective precipitation according to the original NRCS-CN method, it is recommended to assume the moisture level typical for normal conditions (e.g., MHP 2005). The results presented in this article suggest that this approach should be changed in the case of mountain catchments. As it is impossible to compare the calculation results with actual flows in uncontrolled catchments, it is recommended to assume the third level of catchment soil moisture when determining $\mathrm{CN}$ parameter, in order to ensure greater security of flood protection facilities. One should of course remember that the value of $\mathrm{CN}$ parameter needs to be verified in the catchments located in different climatic conditions and of different character than those for which this method was developed (e.g., Krzanowski et al. 2013, Miler 2012). Therefore, a key issue while using the NRCS-CN method is to determine the catchment moisture conditions before a specific flood occurs. This made us attempt to verify other models for estimating the effective precipitation, in which the soil moisture level can be treated in a different way. The presented calculations indicate that in the case of MS and Sahu 1-p model it is also necessary to assume a specific moisture level. According to Sahu et al. (2012), MS method advantageously eliminates sudden jumps in CNs, and hence in computing runoff, through incorporation of the expression of $M$ (Eq. 8), replacing the three AMCs. However, it does not reveal an explicit dependency of $I_{a}$ on $M$. Furthermore, in this method, $S$ is optimized as a parameter, which is, in fact, a varying quan- 
tity depending on $M$ for a given catchment. Hence, it is not clear which moisture level/condition the optimized $S$ would correspond to. A similar situation occurs in the case of Sahu 1-p model. Analysis of calibration and verification results indicates that SME and Sahu 3-p models provide the most accurate values of the direct runoff. In the investigated models, the absolute maximum retention capacity $S_{0}$ was replaced by a potential maximum retention $S$, determined for specific $\mathrm{PNW}_{\text {emp }}$ and $\mathrm{CN}$. This modification was made to enable a direct application of these models in uncontrolled catchments, where there is no possibility of parameter calibration. While making this assumption, a hypothesis was adopted saying that in a mountain catchment with poorly permeable ground, the absolute maximum retention capacity $S_{0}$ may be similar to the potential maximum retention $S$. This hypothesis was supported by the fact that the simulations performed for calibrated values of $S_{0}$ based on the original method yielded very inadequate results. The resulting model quality in the analyzed catchment was similar or even slightly better than reported by, e.g., Sahu et al. (2007, 2010). It is worth emphasizing that the proposed models were applied in a forest-agricultural mountain catchment with the area of over $60 \mathrm{~km}^{2}$, while previous studies mainly focused on agricultural catchments with low slope and area up to 72 hectares. Our analyses of the $Q_{-}$base model showed that using the base flow as a measure of soil moisture in a mountain catchment to calculate $\mathrm{CN}$ parameter was justified, and Eq. 25 is recommended in this case. However, for large $Q_{b}$, the calculated $\mathrm{CN}$ and direct runoff may be unrealistically high. This is due to the very low share of high base flows in the analyzed sample, which causes considerable errors in the calculation regarding the upper part of the regression curve. To verify this hypothesis, it is necessary to carry out further research, based on greater amount of observational data. When using the proposed method, a designer is obviously faced with a serious problem of determining the base flow. It can be determined for monitored water indicators with continuous flow measurements or for periodic stations. Further research should be aimed at generalization of the developed relationships, so that the method could be used in uncontrolled catchments.

\section{CONCLUSIONS}

Based on our study, the following conclusions may be drawn:

- The values of $\mathrm{CN}$ parameter, determined empirically based on recorded rainfall-runoff episodes, differ significantly from the theoretical values, calculated according to NRCS. This indicates the need to verify the value of $\mathrm{CN}$ parameter for local conditions accounting for the course of flood formation in a given catchment. 
- The values of $\mathrm{CN}$ parameter greatly depend on a catchment moisture level prior to the analyzed flood. Using the NRCS recommended criteria for determining the catchment moisture level can result in considerable inaccuracy in determining $\mathrm{CN}$ parameter and calculating the effective precipitation.

- Direct runoff values calculated according to Sahu 3-p and SME models are the most similar to the actually recorded ones. Therefore, these models may constitute an alternative for other methods used for calculating this parameter. Their unquestionable advantage is making the direct runoff independent of variable moisture levels, as proposed in the original NRCS$\mathrm{CN}$ method.

- Knowledge of the base flow value can be useful when calculating $\mathrm{CN}$ parameter. The base flow may characterize the catchment moisture level, as it describes in a more comprehensive manner the hydraulic relations between groundwater and surface waters and, to some extent, the catchment retention capacity.

\section{References}

Banasik, K., and D.E. Woodward (2010), Empirical determination of runoff curve number for a small agricultural watershed in Poland. In: 2nd Joint Federal Interagency Conference, 27 June - 1 July 2010, Las Vegas, USA.

Caviedes-Voullième, D., P. García-Navarro, and J. Murillo (2012), Influence of mesh structure on 2D full shallow water equations and SCS Curve Number simulation of rainfall/runoff events, J. Hydrol. 448-449, 39-59, DOI: 10.1016/j.jhydrol.2012.04.006.

Chauhan, M.S., V. Kumar, and A.K. Rahul (2013), Modelling and quantifying water use efficiency for irrigation project and water supply at large scale, Int. $J$. Adv. Sci. Tech. Res. 3, 5, 617-639.

Cunha, L.K., W.F. Krajewski, R. Mantilla, and L. Cunha (2011), A framework for flood risk assessment under nonstationary conditions or in the absence of historical data, J. Flood Risk Manag. 4, 3-22, DOI: 10.1111/j.1753318X.2010.01085.x.

Deshmukh, D.S., U.C. Chaube, A.E. Hailu, D.A. Gudeta, and M.T. Kassa (2013), Estimation and comparison of curve numbers based on dynamic land use land cover change, observed rainfall-runoff data and land slope, J. Hydrol. 492, 89-101, DOI: $10.1016 / j$ j.jhydrol.2013.04.001.

Ebrahimian, M., A.A.B. Nuruddin, M.A.B.M. Soom, A.M. Sood, and L.J. Neng (2012), Runoff estimation in steep slope watershed with standard and slopeadjusted curve number methods, Pol. J. Environ. Stud. 21, 5, 1191-1202.

Efstratiadis, A., A.D. Koussis, D. Koutsoyiannis, and N. Mamassis (2014), Flood design recipes vs. reality: can predictions for ungauged basins be trusted? 
Nat. Hazards Earth Syst. Sci. 14, 1417-1428, DOI: 10.5194/nhess-14-14172014.

Fan, F., Y. Deng, X. Hu, and Q. Weng (2013), Estimating composite curve number using an improved SCS-CN method with remotely sensed variables in Guangzhou, China, Remote Sens. 5, 3, 1425-1438, DOI: 10.3390/ rs5031425.

Garen, D.C., and D.S. Moore (2005), Curve number hydrology in water quality modeling: uses, abuses, and future directions, J. Am. Water Resour. Assoc. 41, 2, 377-388, DOI: 10.1111/j.1752-1688.2005.tb03742.x.

Geetha, K., S.K. Mishra, T.I. Eldho, A.K. Rastogi, and R.P. Pandey (2007), Modifications to SCS-CN method for long-term hydrologic simulation, J. Irrig. Drain. Eng. 133, 5, 475-486, DOI: 10.1061/(ASCE)0733-9437(2007) 133:5(475).

Grimaldi, S., A. Petroselli, and N. Romano (2013), Green-Ampt Curve-Number mixed procedure as an empirical tool for rainfall-runoff modelling in small and ungauged basins, Hydrol. Process. 27, 8, 1253-1264, DOI: 10.1002/ hyp.9303.

Hawkins, R.H., A.T. Hjelmfelt Jr., and A.W. Zevenbergen (1985), Runoff probability, storm depth, and curve numbers, J. Irrig. Drain. Eng. 111, 4, 330-340, DOI: 10.1061/(ASCE)0733-9437(1985)111:4(330).

Hong, Y., and R.F. Adler (2008), Estimation of global SCS curve numbers using satellite remote sensing and geospatial data, Int. J. Remote Sens. 29, 2, 471477, DOI: $10.1080 / 01431160701264292$.

Kabiri, R., A. Chan, and R. Bai (2013), Comparison of SCS and Green-Ampt methods in surface runoff-flooding simulation for Klang watershed in Malaysia, Open J. Modern Hydrol. 3, 3, 102-114, DOI: 10.4236/ojmh.2013.33014.

Krzanowski, S., A.T. Miler, and A. Wałęa (2013), The effect of moisture conditions on estimation of the $\mathrm{CN}$ parameter value in the mountain catchment, Infrastruc. Ecol. Rural Areas 3, 4, 105-117 (in Polish).

Maidmend, D.R. (1993), Handbook of Hydrology, McGraw-Hill, New York, $1424 \mathrm{pp}$.

McCuen, R.H. (2003), Modeling Hydrologic Change: Statistical Methods, Lewis Publishers/CRC Press, Boca Raton.

Merz, R., and G. Blöschl (2009), A regional analysis of event runoff coefficients with respect to climate and catchment characteristics in Austria, Water Resour. Res. 45, 1, W01405, DOI: 10.1029/2008WR007163.

MHP (2005), Application of Hydrologic Methods in Maryland. Report, Maryland Hydrology Panel, The Maryland State Highway Administration and The Maryland Department of the Environment, Baltimore, USA.

Michel, C., V. Andréassian, and C. Perrin (2005), Soil conservation service curve number method: How to mend a wrong soil moisture accounting procedure, Water Resour. Res. 41, 2, 1-6, W02011, DOI: 10.1029/2004WR003191. 
Miler, A.T. (2012), Influence of land use changes to flood outflows from areas with large afforestation of the Roztocze Środkowe, Infrastruc. Ecol. Rural Areas 2, 1, 173-182 (in Polish).

Mishra, S.K., and V.P. Singh (2002), SCS-CN-based hydrologic simulation package. In: V.P. Singh and D.K. Frevert (eds.), Mathematical Models of Small Watershed Hydrology and Applications, Water Resources Publs., LLC, Highlands Ranch, 391-464.

Mishra, S.K., and V.P. Singh (2003a), Soil Conservation Service Curve Number (SCS-CN) Methodology, Kluwer Academic Publ., Dordrecht.

Mishra, S.K., and V.P. Singh (2003b), Derivation of the SCS-CN parameter S from linearized Fokker-Planck equation, Acta Geophys. Pol. 51, 2, 179-202.

Mishra, S.K., M.K. Jain, P.K. Bhunya, and V.P. Singh (2005), Field applicability of the SCS-CN-based Mishra-Singh general model and its variants, Water Resour. Manag. 19, 1, 37-62, DOI: 10.1007/s11269-005-1076-3.

Mishra, S.K., S. Gajbhiye, and A. Pandey (2013), Estimation of design runoff curve numbers for Narmada watersheds (India), J. Appl. Water Eng. Res. 1, 1, 6979, DOI: $10.1080 / 23249676.2013 .831583$.

Moriasi, D.N., J.G. Arnold, M.W. van Liew, R.L. Bingner, R.D. Harmel, and T.L. Veith (2007), Model evaluation guidelines for systematic quantification of accuracy in watershed simulations, Trans. Am. Soc. Agricult. Biol. Eng. 50, 3, 885-900.

Nash, J.E., and J.V. Sutcliffe (1970), River flow forecasting through conceptual models: Part I - A discussion of principles, J. Hydrol. 10, 3, 282-290, DOI: 10.1016/0022-1694(70)90255-6.

Petroselli, A., S. Grimaldi, and N. Romano (2013), Curve-Number/Green-Ampt mixed procedure for net rainfall estimation: A case study of the Mignone watershed, IT, Procedia Environ. Sci. 19, 113-121, DOI: 10.1016/j.proenv. 2013.06.013.

Ponce, V.M. (1989), Engineering Hydrology: Principles and Practices, Prentice Hall, Englewood Cliffs.

Ponce, V.M., and R.H. Hawkins (1996), Runoff curve number: Has it reached maturity? J. Hydrol. Eng. 1, 1, 11-19, DOI: 10.1061/(ASCE)1084-0699(1996) $1: 1(11)$.

Sahu, R.K., S.K. Mishra, T.I. Eldho, and M.K. Jain (2007), An advanced soil moisture accounting procedure for SCS curve number method, Hydrol. Process. 21, 21, 2872-2881, DOI: 10.1002/hyp.6503.

Sahu, R.K., S.K. Mishra, and T.I. Eldho (2010), An improved AMC-coupled runoff curve number model, Hydrol. Process. 24, 20, 2834-2839, DOI: 10.1002/ hyp.7695.

Sahu, R.K., S.K. Mishra, and T.I. Eldho (2012), Performance evaluation of modified versions of SCS curve number method for two watersheds of Maharashtra, 
India, ISH J. Hydraul. Eng. 18, 1, 27-36, DOI: 10.1080/09715010.2012. 662425.

SCS (1956), SCS National Engineering Handbook. Section 4. Hydrology. Supplement A, Chp. 10, Soil Conservation Service, US Dept. of Agriculture, Washington, USA.

Smith, R.E., and J.R. Williams (1980), Simulation of the surface water hydrology. In: W.G. Knisel (ed.), CREAMS: A Field-scale Model for Chemicals, Runoff, and Erosion from Agricultural Management Systems, Conservation Research Report No. 26, US Dept. of Agriculture, Washington, USA, 165 192.

Váňová, V., and J. Langhammer (2011), Modelling the impact of land cover changes on flood mitigation in the upper Lužnice basin, J. Hydrol. Hydromech. 59, 4, 262-274, DOI: 10.2478/v10098-011-0022-8.

Wałęga, A., A. Cupak, and W. Miernik (2011), Influence of entrance parameters on maximum flow quantity receive from NRCS-UH model, Infrastruc. Ecol. Rural Areas 7, 85-95 (in Polish).

Wałęga, A., E. Drożdżal, M. Piórecki, and R. Radoń (2012), Some problems of hydrology modelling of outflow from ungauged catchments with aspects of flood maps design, Acta Scient. Polon. Format. Circum. 11, 3, 57-68 (in Polish).

Woodward, D.E., C.C. Hoeft, R.H. Hawkins, J. van Mullem, and T.J. Ward (2010), Discussion of "Modifications to SCS-CN method for long-term hydrologic simulation" by K. Geetha, S.K. Mishra, T.I. Eldho, A.K. Rastogi, and R.P. Pandey, J. Irrig. Drain. Eng. 136, 6, 444-446, DOI: 10.1061/(ASCE) IR.1943-4774.0000231.

Received 15 April 2014 Received in revised form 22 October 2014 Accepted 19 January 2015 